\title{
APRESENTAÇÃO A vida social é atualizar reciprocidades
}

\author{
Ana Luiza Carvalho da Rocha \\ Cornelia Eckert ${ }^{1}$ \\ Universidade Federal do Rio Grande do Sul
}

$\mathrm{E}$ m 2007 os alunos do Programa de Pós-graduação em Antropologia Social e do Programa de Pós-Graduação Interdisciplinar em Ciências Humanas da Universidade Federal de Santa Catarina aceitaram o desafio de realizar uma Jornada de Estudos sobre a obra de Georg Simmel.

Chamaram este acontecimento de encontro inter-tribal, convidando alunos da Universidade Federal do Rio Grande do Sul e a nós para compartilhar os resultados das pesquisas e dos estudos inspirados na obra de Georg Simmel. Pouco tempo antes tivemos a oportunidade, na condição de professoras visitantes e a convite da Dra. Carmen Rial, de dividir uma disciplina sobre estudos das sociedades complexas com esta geração de estudantes.

Nosso sentimento de que algo especial iria acontecer foi confirmado ao encontrar no dia do evento, uma roda de participantes, alunos e professores, circulando a palavra para o relato das experiências de pesquisa e aprendizados suscitadas pela obra do mestre homenageado. Nada mais apropriado do que um encontro regado a trocas sociais para entender o estudo de Simmel sobre a socialização como um processo.

$\mathrm{Na}$ condição de discípulas do mestre acompanhamos a fecundidade da discussão neste evento simmeliano. Nada pode alegrar mais um professor do que ouvir as ressonâncias da transmissão de um saber no trabalho dos seus alunos e, neste caso, dos diálogos que esta "tribo" teceu a partir da produção intelectual de Simmel, esta, aliás, pioneira e ousada para o final do século XIX.

Para contribuir com comentários sobre o impacto que este intelectual provocou em todos nós que pesquisamos na cidade, não há como inventar nenhuma nova notícia, nem tempo para inventariar tantos estudos primorosos dedicados a sua obra, alguns, aliás, realizados por autores brasileiros como Simone Maldonado e Leopoldo Waizbort. Pensamos, então, em apenas repetir o que de modo geral colocamos aos nossos alunos, quando pela primeira vez em sala de aula, se deparam com a obra de Georg Simmel. Começamos por informar acerca da singularidade do aporte teórico deste autor para os estudos em torno da vida cotidiana nas grandes metrópoles a partir de uma perspectiva sociológica e antropológica.

\footnotetext{
${ }^{1}$ Endereço para correspondências: Universidade Federal do Rio Grande do Sul, Instituto de Filosofia e Ciências Humanas, Programa de Pós-Graduação em Antropologia Social, Laboratório de Antropologia Social (anarocha.ez@terra.com.br e corneliaeckert@terra.com.br).

${ }^{2}$ Sobre o conceito de etnografia da duração, ver Eckert e Rocha (2000).
} 
A intenção é seduzir os alunos-leitores a conhecerem uma contribuição teórica e intelectual que os obrigará necessariamente aos primeiros deslocamentos epistemológicos sobre sua própria forma de vida social - as modernas sociedades urbano-industriais - rompendo com sensos comuns de antigas cartilhas sobre o que vem a ser a vida social.

O convite desafiador é, assim, a leitura da complexa produção intelectual de Georg Simmel sobre as formas da vida social, sobre o amor, sobre a prostituição, sobre a paisagem, sobre o estrangeiro, sobre o feminino, a arte, a estética, a moda, a ruína, sobre temas tão diversos quanto às formas de sociação da vida humana. Processamos, então, certa iniciação à obra de Simmel desde o impacto de sua obra no pensamento social contemporâneo a como esta convergia com questões que poucos se aventuraram em formular em sua época, como por exemplo, perguntar sobre como é possível a sociedade? Vamos imaginar este intelectual do século XIX em sua aventura compreensiva de uma variedade de formas de vida social que qualificam a vida moderna. Nesta perspectiva começamos nos dando conta das diferenças que Georg Simmel estabelece entre as formas de vida social e os conteúdos que elas carregam. Para este autor importa menos o conteúdo dado nas relações sociais, e mais, as formas como as ações recíprocas são vividas na vida cotidiana, atualizando assim a sociedade, e de certa forma, estetizando o cotidiano como um drama social.

Nesta perspectiva, fica evidente como, na época, a obra de Simmel rompeu com as explicações gerais dos intelectuais sobre a realidade da vida social. Sua obra, ao contrário, estimulava as ditas ciências sociais à estudos "situados", onde cada micro mundo era desvendado permitindo uma variedade de interpretações sobre assuntos ainda inéditos nas ciências sociais. Para o autor, o nó da questão era dimensionar como estavam se tornando complexas as formas de reciprocidade nas sociedades modernas, relacionadas aos valores que portavam o dinheiro e o individualismo, e mais ainda, como elas se transformando, podiam perdurar no tempo.

Georg Simmel, em sua época, então se indagava: Que figura de homem é esta que se gera no mundo moderno? A diferença da questão postulada por Émile Durkheim (1858-1917) - que nesta mesma época se perguntava sobre como funcionava a sociedade - Simmel perguntava como vivemos em sociedade, ou como a sociedade é possível. Vivendo sua época, um mundo marcado pela ascensão do valor do indivíduo moderno, ele propunha uma fórmula interrogativa sobre a tensão entre a cultura objetiva e a cultura subjetiva, e isto implicava em dar conta da agitação dessa época, da vida urbana marcada por altas densidades demográficas e onde os habitantes se tornavam cada vez mais indiferentes a tantas complexidades.

Damos-nos conta, então, que o convite para a leitura da obra de Simmel passa, assim, a compreender o exame atento e sensível da cultura moderna 
como um conjunto de formas significativas onde as relações econômicas de troca, marcadas pela legalidade racional, se tornam insuficientes por si mesmas no estabelecimento de vínculos duradouros entre os homens. Para Simmel se torna evidente que não basta pensar a vida social a partir de suas instituições; normas e regras formalistas; (a sociedade como) fato moral ou escolha racional, mas como uma rede de trocas sociais e afetivas recíprocas, sempre renovadas para além do seu impulso inicial de fundação, num processo incansável de configuração. Isto é, trata-se da dimensão vital do princípio de agregação de toda vida social e a importância da dimensão formal para a compreensão do instante em que os processos de sociação emergem. Para o autor, os laços sociais perseguem tais fluxos da experiência vivida, ganhando formas que persistem para além dos seus conteúdos de origem.

Pode-se dizer que Simmel, revisando os estudos de Immanuel Kant (17241804), Arthur Schopenhauer (1788-1860), Friedrich Nietzsche (1844-1900) e mais ainda, circulando comodamente por diferentes campos de conhecimento como filosofia, história, antropologia, sociologia, economia, arte, estética, urbanismo, psicologia, buscava criar uma sociologia compreensiva. Nisto ele não era pioneiro, outros já o haviam antecedido e vamos nos referir entre outros a Max Weber (1881-1961), que lançou as bases teóricas para questionar sobre um espírito de época, o capitalismo.

Em sua feição singular, cabe reconhecer o fato de que Simmel aprofunda a análise da modernidade ao atribuir à crise uma dinâmica intrínseca da própria conformação (formação-com) da vida social, sempre grávida de questões sobre conflitos e sensibilidades que orientavam as formas plurais de interação social, os estados psíquicos e valores éticos do homem moderno, formas de confiança e de desconfiança, de aproximação e de estranhamento, de solidariedade e de exclusão. Diferente do pensamento hegemônico de sua época, para Simmel, o homem moderno é livre, livre para viver em reciprocidade e jogar no social. Para ele, jogar o social revela o laço social em seu de fluxo das experiências, as quais despontam como fonte de energia que alimenta as relações de reciprocidade entre os indivíduos, figurando aproximações e afastamentos desde seus efeitos de co-presença no conjunto das relações entre os indivíduos. Neste ponto não se poderia pensar o pensamento de Simmel, nas palavras de Gabriel Cohn (1998), nem a partir de um "modelo da ação significativa, nem a um modelo do caráter representacional do simbolismo cultural". Assim, em outros termos: nem Max Weber, nem Émile Durkheim, nem mesmo Marcel Mauss (1872-1950).

Para o pensamento de Simmel sobre a vida social, os efeitos de sociação não transcorrem de uma divisão do trabalho, mas de gestos e sentimentos recíprocos através dos quais as relações sociais se multiplicam e pela via das formas colocam os indivíduos continuamente em contato, introduzindo-se nisto novas fontes de trocas pela assimetria de suas motivações e interesses que promovem. 


\section{HüAnas}

A perdurância das formas de vida social para Simmel são, portanto, uma fonte constante de reflexão uma vez que não se explicam por uma mera solução normativa e sistêmica da organização da vida social em esferas, nem tampouco por uma força moral de dever auto-imposto. A perdurância da reciprocidade das ações sociais e a persistência de seus conteúdos psíquicos fugazes independem das contingências da própria vida social, assegurada nos modelos prescritos pelas instituições, e das suas regulamentações normativas e legais. Segundo o pensamento simmeliano não julgamos a vida social, pois devemos nos acercar dela desde o interminável inventário de suas formas concretas, aquelas que nascem da experiência societária entre os indivíduos em suas aproximações e afastamentos recíprocos, segundo seus sentimentos e afetos.

Disto resulta que a perpetuidade da vida social não esta determinada pela ação puramente racional, nem por imposições legais de qualquer ordem, mas da continuidade da interação dada no jogo da vida social, de dar e de receber, e das formas que atribuem tonalidades singulares a tais laços de reciprocidade entre os homens. Em Simmel, podemos pensar a vida dos afetos (o amor, a sedução, a gratidão) longe do formalismo pernicioso de qualquer conteúdo, para despontar simplesmente como um principio de "con-figuração" do próprio laço social (resíduo subjetivo e memória moral da humanidade), gerador de pontes entre seres humanos e, portanto, propiciadora da constituição e permanência do próprio jogo social para além do momento da sua criação. O laço social e não mais o sentimento que propiciou o laço é, então, que se torna mais significativo; ou seja, a forma como capacidade de converter o impulso inicial em interações re-interadas, atribuindo-lhes uma tonalidade, uma atmosfera, pela proximidade dos sentimentos através dos quais os seres humanos se co-respondem no interior de uma dada situação social.

Estamos em pleno exercício de compreensão do papel das formas da vida social no pensamento de Simmel. Passamos de uma reflexão em torno do tema das formas dos laços sociais para o das relações das próprias formas entre si tanto quanto das relações entre tais formas e os conteúdos que adotam no interior da experiência vivida no jogo social. A dinâmica da experiência vivida e seus arranjos tornam-se dimensões relevantes para se pensar como os conteúdos dos laços sociais se expressam através das formas sociais que as condicionam, assim como refletir como tais formas sociais e culturais assimilam a diversidade das experiências que acolhem.

Logo, é na centralidade do paradigma da forma em Simmel é que podemos perceber o quanto o autor é sensível aos traços paradoxais da experiência de vida social metropolitana que o mundo moderno expressa. As transformações das formas da vida social e cultural são intensas e é esta dinâmica que provoca as mudanças de sentido no papel do dinheiro, da religião, da arte, da política, da estética na vida urbana. Uma via que mais do que dupla, é dialética. 
A vida social é atualizar reciprocidades Ana Luiza Carvalho da Rocha e Cornelia Eckert

Transformações carregadas de conflitos na vida social e na vida individual, mas que acabam por configurar formas de interação no interior da qual a vida social perdura. Em Simmel trata-se da relação entre a experiência vivida no mundo moderno e as formas de vínculos sociais que ela assume em relação a outras formas e experiências de vida social. Para ele o problema não consistiria na condição contingente da vida metropolitana sobre a vida do espírito, mas no caráter fugaz, dinâmico e efêmero que a vida moderna suscita para a questão da persistência, mais do que a da estabilização das formas sociais.

Este momento é especial para mostrarmos nossa adesão a obra de Simmel e no caso de nosso projeto de pesquisa, mostrar que tratamos do tema das formas de sociabilidade e da memória coletiva no mundo urbano contemporâneo a partir de pesquisas etnográficas nas cidades, em especial na cidade de Porto Alegre (RS, Brasil). Partimos da questão de como podemos pensar, as formas sociais nas modernas sociedades complexas urbano-industriais, como enquadramentos gerados pelo fluxo das experiências vividas por seus habitantes, tanto quanto pensar, tais formas, como arranjos da vida social que permitem reunir entre si, num fluxo ilimitado de experiências possíveis, as totalidades do social e do individual no corpo da memória coletiva.

Para aqueles que investigam a memória coletiva e o patrimônio etnológico no mundo contemporâneo este momento preciso em que o autor passa a refletir sobre o(s) processo(s) de associação/dissociação, de separação/reaproximação, associação/dissociação é fundamental na delimitação do que denominamos a etnografia da duração ${ }^{2}$. O tema da descontinuidade espaçotemporal como fenômeno inerente as formas sociais transparece de forma evidenciada em vários momentos do pensamento do autor. Simmel em seu ensaio sobre a porta e a ponte reconhece a disjunção como princípio da reciprocidade entre as dimensões espaciais e temporais que organizam os arranjos da vida social, e lhe permitindo, neste sentido, uma duração. Para o autor, "é preciso primeiro que as coisas estejam umas fora das outras para estarem em seguida umas com as outras". Refletindo sobre as diversidades das formas dos territórios de vida social, ele conclui: "os primeiros homens que traçaram um caminho entre dois lugares, cumpriram uma das maiores tarefas humanas. Mesmo que podendo circular de um lugar para outro, ligando-os por assim dizer subjetivamente, ainda foi necessário que gravassem visivelmente o caminho sobre a terra para que esses lugares pudessem ser ligados de novo; o desejo de junção passava então a ser uma tomada de forma das coisas oferecidas" (SIMMEL, 1996; p. 10).

Por um lado, desde o pensamento simmeliano, a ponte tratar-se-ia de uma metáfora do tempo capaz de reunir a experiência humana na sociedade numa totalidade desde a sociação estável de segmentos de espaços. A ponte como metáfora para a "esfera volitiva do homem no espaço", uniria partes da paisagem, 
reaproximando extremidades e compondo o caminho. Por outro lado, a porta revelaria a metáfora das formas da vida social, que se joga no plano terrestre, como possibilidades da construção de perspectivas associativas/dissociativas. Para Simmel, a vida social joga a cada instante uma ponte entre as coisas despojadas de lugar, ela se encontra tanto no interior como no exterior da porta em cada um desses instantes, porta por onde ela sai do seu ser-para-si a fim de entrar no mundo, na mesma medida em que ela sai do mundo para entrar de novo no seu ser-para-si. Na visibilidade imediata do espaço de existência de uma forma social "a separação e reaproximação nada mais são do que dois aspectos do mesmo ato, ao mesmo tempo uma porção de espaço se encontra assim ligado a si e cindido de todo o resto do mundo" (SIMMEL, 1996; p. 12).

A vida social, portanto, não pode prescindir de formas tanto quanto a existência humana esta inexoravelmente reunida em torno de uma tragédia, uma vez que "o homem é o ser de ligação que deve sempre separar, e que não pode religar sem ter antes separado - precisamos primeiro conceber espírito como uma separação a existência indiferente de duas margens, para ligá-las por meio de uma ponte" (SIMMEL, 1996; p. 14). Segundo Simmel, o homem é de tal maneira um ser-fronteira, que não tem fronteira, indeterminado, portador em si-mesmo de um princípio contraditório, "unido a cadeia sem fim das coisas, do nascimento ao aniquilamento ininterruptos das formas, sendo a sociação entre homens o resultado de uma unidade fluida do vir-a-ser, exprimindo-se através da continuidade da existência espacial e temporal" (SIMMEL, 1996; p. 15).

Para Simmel, usando a força de sentido das suas próprias palavras, da simples dinâmica do movimento, em cuja efetividade vem se esgotar a cada vez, o "objetivo" da ponte se faz visualmente durável, assim como o quadro imobiliza à sua maneira o processo vital, físico e psíquico pelo qual se cumpre a realidade do homem, isto é, estável pela sua intemporalidade, como não mostra nem pode mostrar a realidade factual - toda a agitação desta realidade que decorre no tempo (SIMMEL, 1996; p. 11).

Coagular o movimento por uma estrutura sólida, nos termos de Simmel a ponte revela que a noção de separação estaria despojada de sentido se não houvéssemos começado por uni-las, nos nossos pensamentos finalizados, nas nossas necessidades, na nossa imaginação (SIMMEL, 1996).

Afirmação preciosa onde o autor reconhece a participação da imaginação fabuladora como fenômeno que integra o próprio processo de consolidação da duração dos arranjos da vida social no tempo, através da imagem de uma causalidade formal necessária para que a sua matéria adquira, finalmente, uma causalidade material. 
A vida social é atualizar reciprocidades Ana Luiza Carvalho da Rocha e Cornelia Eckert

O pensamento fecundo de Simmel nos apresenta, assim, o desafio de se compreender a duração da vida social desde as formas onde seus conteúdos se expressam? Ou seja, é na infinitude e na descontinuidade de jogar no social que se vislumbram sentimentos de pertença ou de indiferença, de evitação ou de configuração de uma rede de sociabilidade. A vida social dura nas descontinuidades das formas. O importante é não parar de jogar. Este é um perigo constante que Simmel denominará de tragédia da cultura. Ele orientará de que, em determinadas situações sociais, as motivações das relações podem se objetivar de tal forma que se colocam como autônomas e institucionais, fugindo das regras do jogo da reciprocidade de não estabilizar, não cimentar, ameaçando a continuidade de laços sociais se darem no fluxo da descontinuidade temporal.

Em pleno exercício de se pensar o tempo e a memória no jogo das formas sociais no interior das modernas sociedades complexas e como instâncias possíveis de uma etnografia da duração temos com Simmel que a cultura moderna resultaria da dissolução das ligações e das relações originais das formas de vida interiores e exteriores em benefício de realidades autônomas de caráter diferenciado (SIMMEL, 1996; p. 16).

Se nos ensaios de Simmel sobre o dinheiro, a moda, o feminino, a paisagem, a vida moderna se apresenta desde a causalidade formal dos processos de racionalização e objetivação dos laços sociais, da configuração de relações sociais mais neutras, mais deserotizadas, mais livres, sujeitas tanto ao isolamento quanto ao desenraizamento, por seu turno, este mesmo autor constrói sua análise das formas de vida social sempre referida à interdependência dos laços estreitos de interação social, configuradas desde o princípio unificador dos sentimentos e dos afetos que engendram os laços de reciprocidade entre os homens e lhes atribui colorações e tonalidades singulares como obra da cultura humana. Nos termos de Michel Maffesoli, ao mesmo tempo, circulação de mercadorias e objetos e circulação de pessoas e palavras, nas grandes metrópoles as formas sociais ainda que sejam apresentadas por Simmel como antinomias entre a vida do intelecto e a vida dos nervos, entre impressões externas e internas, guardam os valores da luta e de reconciliação do destino humano no cosmos (MAFFESOLI, 2001).

A leitura contemporânea da obra de Simmel nos permite, assim, compreender as complexas e imbricadas relações entre a exterioridade das formas da vida social - e suas formas de alteridades - e as modalidades dos laços de reciprocidade, ambos como instâncias estruturais das sociedades humanas em sua fluidez e efemeridade. O social é, neste sentido, uma passagem constante de uma forma/estado à outra, nos termos de Michel Maffesoli (2001), perpétuo devir, errância dos afetos, das pessoas e das palavras e onde estabilidade e instabilidade se conjugam numa harmonia conflitual. 


\section{HüANAs}

Viver em sociedade é acima de tudo animação, jogo marcado pela vibração dos arranjos sociais onde a forma informe dos laços sociais - realidade movente - se faz e desfaz no interior da agregação social. Como não pensar aqui o fator tempo ritmando o caráter dos laços sociativos, orquestrando sua dinâmica imaterial para a produção material e concreta de um corpo social e de seus espaços e territórios. Segundo Michel Maffesoli, sob o ponto de vista da sociedade, desde a experiência vivida e da vida dos afetos, a percepção simmeliana do afetual e do sensível - como condição das formas de agregação social - não se coloca como tarefa das mais simples para nós, cientistas sociais, geralmente acostumados à segurança e à proteção de nossas análises sociológicas sobre a vida social e os seus princípios seguros da individuação. Neste sentido, a densidade das análises de Georg Simmel da vida cotidiana na cidade moderna contrasta com as análises, durkheimiana e parsoniana, da vida social a partir das forças impessoais das instituições e dos papéis sociais.

Nunca é demais insistir que para Simmel, no arranjo da vida social, a forma é condição para que os "laços sociativos" possam ganhar persistência no tempo, tornando-se independentes da sua fonte de origem. Através das formas o social se permite como experiência reiterada do estar próximo, através dos sentimentos correspondentes que ela evoca. E tendo em vista a própria labilidade do social, a duração das formas sociais só pode ser pensada desde uma fonte de interdependência entre conflito e comunhão.

Orientados pela Escola de Chicago, e aproximando-nos mais uma vez da perspectiva de Georg Simmel através da prática etnográfica, podemos aderir a sua aventura na tentativa de interpretar a atualização dos laços e das reciprocidades em pleno contexto das modernas sociedades urbano-industriais. Seguimos sua premissa de que o jogo social não se trata de simples repetição de modelos e papéis de ontem, mas de um perpétuo devir, ultrapassando-se as ameaças da tragédia da cultura para simplesmente continuar a criar e recriar a própria vida no interior do social.

Ainda que por vezes contaminado por um tom melancólico, o pensamento simmeliano sobre o mundo moderno nos desafia a pensar a paralisia da vida social fundada no individualismo, a partir da exacerbação da vida dos sentidos. Um ponto importante para este pensador - que não se cansa de reconhecer o papel do plural na vida social - pela via da inclusão do caráter conflitual da vida social, seria o de contrapor, a idéia de vida social como produto impessoal das trocas formais entre grupos, a dimensão afetiva e sensível dos laços de reciprocidade entre micro-grupos sociais. O que nos leva ao princípio da reciprocidade e que nos conduz hoje a estar participando deste encontro inter-tribal onde o jogo social se manifesta desde a aventura da diversidade das trocas intelectuais e afetivas que nos propusemos como pesquisadores. 
Ana Luiza Carvalho da Rocha e Cornelia Eckert

\section{Referências bibliográficas}

COHN, G. As diferenças finas, de Simmel a Luhmann. Revista Brasileira de Ciências Sociais, 13(38), São Paulo, 1998.

ECKERT, C. \& DA ROCHA, A.L.C. Imagens do tempo nos meandros da memória: por uma etnografia da duração. In: M.G.P. Koury (Org.). Imagem e memória: estudos em Antropologia visual. Pp. 19-39. Rio de Janeiro: Garamond, 2000.

MAFFESOLI, M. Une lecture de Georg Simmel. Revue des Sciences Humaines et Sociales, 74, Paris, Dunod, 2001.

MORAES FILHO, E. (Org.). Simmel. São Paulo: Ática, 1983.

SIMMEL, G. A ponte e a porta. Revista Política \& Trabalho, 12(Setembro): 10-14, 1996.

SIMMEL, G. Comment les formes sociales se maintiennent. In: Sociologie et epistémologie. Paris: PUF, 1981.

SIMMEL, G. Filosofia da paisagem. Revista Política \& Trabalho 12(Setembro): 15-24, 1996.

SIMMEL, G. Le problème de la Sociologie. In: Sociologie et epistémologie. Paris: PUF, 1981.

SIMMEL, G. Questões fundamentais da Sociologia. Rio de Janeiro: Jorge Zahar, 2006.

WAIZBORT, L. As aventuras de Georg Simmel. São Paulo, Editora 34, 2000. 